\title{
BMJ Open Electromyographic activity of preterm newborns in the kangaroo position: a cohort study
}

\author{
Rafael Moura Miranda, ${ }^{1}$ José Eulálio Cabral Filho, ${ }^{1}$ Kaísa Trovão Diniz, ${ }^{1}$ \\ Geisy Maria Souza Lima, ${ }^{2}$ Danilo de Almeida Vasconcelos ${ }^{1}$
}

To cite: Miranda RM, Cabral Filho JE, Diniz KT, et al. Electromyographic activity of preterm newborns in the kangaroo position: a cohort study. BMJ Open 2014;4:e005560.

doi:10.1136/bmjopen-2014005560

- Prepublication history for this paper is available online. To view these files please visit the journal online (http://dx.doi.org/10.1136/ bmjopen-2014-005560).

Received 25 April 2014 Revised 2 September 2014 Accepted 5 September 2014

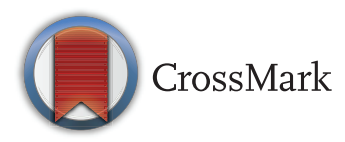

${ }^{1}$ Post Graduate Program of Instituto de Medicina Integral Prof. Fernando Figueira (IMIP), Recife, Brazil

${ }^{2}$ Instituto de Medicina Integral Prof. Fernando Figueira (IMIP), Recife, Brazil

Correspondence to Dr Rafael Moura Miranda; rafael.mm@hotmail.com

\section{ABSTRACT}

Objective: To compare the electromyographic activity of preterm newborns placed in the kangaroo position with the activity of newborns not placed in this position.

Design: A cohort study.

Setting: A Kangaroo Unit sector and a Nursery sector in a secondary and tertiary care at a mother-child hospital in Recife, Brazil.

Participants: Preterm infants of gestational age 27-34 weeks $(n=38)$ and term infants $(n=39)$.

Primary and secondary outcome measures: Surface electromyography was used to investigate muscle activity in the brachial biceps at rest. 3 groups were designed: (1) preterm newborns in the kangaroo position (PT-KAN), where the newborn remains in a vertical position, lying face down, with limbs flexed, dressed in light clothes, maintaining skin-to-skin contact with the adult's thorax. Her electromyographic activity was recorded at $0 \mathrm{~h}$ (immediately before starting this position), and then at $48 \mathrm{~h}$ after the beginning of the position (but newborns were kept in the kangaroo position for 8-12 $\mathrm{h}$ per day) and at term equivalent age ( $40 \pm 1$ weeks); (2) preterm newborns not in the kangaroo position (PT-NKAN), in which measurements were made at $0 \mathrm{~h}$ and $48 \mathrm{~h}$; and (3) term newborns $(\mathrm{T})$, in which measurements were made at $24 \mathrm{~h}$ of chronological age.

Results: The Root Mean Square (RMS) values showed significant differences among groups $\left(F_{(5,108)}=56.69 ; p<0.001\right)$. The multiple comparisons showed that RMS was greater at $48 \mathrm{~h}$ compared to $0 \mathrm{~h}$ in the preterm group in the kangaroo position, but not in the group not submitted in the kangaroo position. The RMS in the term equivalent aged group in the kangaroo position was also greater when compared with those in the term group.

Conclusions: The kangaroo position increases electromyographic activity in the brachial biceps of preterm newborns and those who have reached the age equivalent to term.

\section{INTRODUCTION}

The kangaroo method (KM) is a kind of intervention that aims to improve the health

\section{Strengths and limitations of this study}

- The results of the study add new information about the effects of Kangaroo-Mother Care for the preterm.

- The early initiation of the kangaroo position may, like other early intervention programmes, have a positive influence on the motor responses of the neonate, thereby making it possible to influence the motor development of the preterm newborn.

- It is important to point out the innovative nature of this study, since there is a lack of studies specifically evaluating electromyographic activity in newborns in the kangaroo position.

- A sample size lower than the estimate in one of the groups preterm newborns not in the kangaroo position (PT-NKAN) is a factor that may diminish the reliability of our findings. However, the sample power of $90 \%$, the large differences found between the means and the statistically significant results, may support our inference.

of low-weight preterm newborns. ${ }^{1}$ There is evidence that the method provides various benefits. These benefits include an increase in body temperature, ${ }^{2}{ }^{3}$ stabilisation of cardiorespiratory frequency, ${ }^{3}{ }^{4}$ improved brain oxygenation, ${ }^{5}$ behaviour improvement (crying and sleep), ${ }^{6-8}$ pain reduction ${ }^{4} 910$ and greater adherence and duration of breastfeeding. ${ }^{11-13}$ The method is also associated with a reduction in morbidity and mortality, ${ }^{14}{ }^{15}$ infections ${ }^{14}$ and hospital stay. ${ }^{15}$

The main feature of the method is the kangaroo position, whereby the newborn remains in a vertical position, with limbs flexed, dressed in light clothes, maintaining skin-to-skin contact and the face on the adult's thorax. ${ }^{1}$ This position allows neonates to receive sensory, vestibular and postural stimuli, and the effects on motor responses in newborns has thus aroused some interest among investigators. ${ }^{16}$ Recently, some studies ${ }^{16} 17$ have shown an increase in electromyographic activity in preterm newborns 
after different periods of time in the kangaroo position (up to $96 \mathrm{~h}$ ), and this increase persists until an age equivalent to term. These results were pioneering, although no study has yet been conducted in which these responses have been compared with those of preterm newborns not in the kangaroo position (PT-NKAN) and those of term newborns. The aim of the present study was thus to compare electromyographic activity in preterm newborns in the kangaroo position (PT-KAN) and the activity of newborns not placed in this position.

\section{METHODS}

\section{Participants}

This cohort study was carried out between July 2012 and January 2013 at the Instituto de Medicina Integral Prof. Fernando Figueira (IMIP), in Recife, Brazil. Sixty-four hospitalised newborns were included in the study: 38 preterm infants (in the Kangaroo Unit sector) and 26 term infants (in the Nursery sector).

The IMIP's Kangaroo Unit covers a surface-area of $600 \mathrm{~m}^{2}$ and has a ward with 22 beds for clinically stable preterm newborns (with a respiratory frequency of between 30 and 60 inspirations per minute, a heart rate of between 120 and 160 beats per minute, peripheric oxygen saturation of over $89 \%$, absence of signs of respiratory distress and signs of cyanosis or pallor and pain) The newborns had to tolerate food, breathe without the use of any equipment and weigh more than $1250 \mathrm{~g}$.

The Kangaroo Unit provides medical and nursing services and also speech therapy and physiotherapy. In this unit, the newborns referred to medical services are evaluated and undergo an early stimulation programme.

Newborns were included in the preterm groups if they had a gestational age of 27-34 weeks and a corrected age of until 35 weeks at the time of the first electromyographic examination, and had not previously been in the kangaroo position. Neonates were included in the term group if they had a gestational age of 38-41 weeks. They were only included when their Brazelton state during the electromyographic recording was 4 or 5 (inactive alert or alert with activity).

The exclusion factors for all the newborns were: Apgar lower than 7 in the 5th min, a history of grade III or IV intracranial haemorrhage (diagnosed by way of transfontanelar ultrasound and included in the medical records), seizures, congenital infections (cytomegalovirus, rubella, toxoplasmosis, syphilis and vertically transmitted HIV), malformations of the central nervous system (hydrocephaly and genetic syndromes), infections of the central nervous system (meningitis or encephalitis), congenital cardiopathy, traumas during delivery (injuries to the brachial plexus, dislocation of the hip and pelvis fractures) and gastro-oesophageal reflux disorder.

All these inclusion and exclusion factors were evaluated using collected data from patients' medical records evaluated by neonatologists at the Neonatal Intensive Care Unit, the Kangaroo Unit sector and the Nursery sector.

A convenient non-probabilistic sequential sample was obtained from the newborns. The size of the sample was calculated based on a previous study ${ }^{17}$ that found a variance of 2.6 in the electromyographic activity and estimated the minimum difference between means of $2 \mu \mathrm{V}$. With an $\alpha$ error of 0.05 and a power of $90 \%$, the sample size result was 21 individuals for each group.

The parents or guardians who agreed to participate in the study signed the free informed consent.

\section{Collection procedure}

The electromyographic signal was obtained using a Miotool 400 electromyography device (Miotec Equipamentos Biomédicos-Brazil). A system of channels and a self-adhesive $4.2 \mathrm{~mm}$ diameter $\mathrm{Ag} / \mathrm{AgCl}$ electrode (Meditrace 100) were used to connect the equipment to the newborn's body at examination. The electromyography device was connected to a laptop using Myographic V.2.0 software (Miotec Equipamentos Biomédicos-Brazil) to process the myoelectrical records. The sampling frequency was $2000 \mathrm{~Hz}$ and the electromyograms were amplified 2000 times.

The electromyographic signal was captured using two surface electrodes placed on the central portion of the left brachial biceps muscle, between the motor point and the myotendinous junction, parallel to the muscle fibres, as recommended by the SENIAM (Surface Electromyography for the Non-Invasive Assessment of Muscles) project. ${ }^{18}$ The electrodes were adjusted to ensure that the distance between them could not exceed more than $20 \mathrm{~mm}$ and the reference electrode was always placed on the lateral malleolus contralateral to the muscle under evaluation.

Before the measurements were performed, the newborn was placed on a small wedge-shaped cushion at an angle of $30^{\circ}$ relative to the horizontal plane. The electromyographic activity captured the newborns in Brazelton state 4 or 5 (inactive alert or alert with activity), respectively. ${ }^{19}$

There were three designed groups: group $1 \quad(n=25)$ : PT-KAN; (2) group 2 (n=13): PT-NKAN; and (3) group $3(\mathrm{n}=26)$ : term newborns $(\mathrm{T})$.

In the PT-KAN group, electromyographic activity was first recorded before the neonates were in the kangaroo position $(0 \mathrm{~h})$. Immediately after taking this record, the neonates were placed for the first time in the kangaroo position. The kangaroo position adopted was as recommended by the Kangaroo Unit, in which the newborn is positioned in the adult's breasts, face down, should be dressed in light clothes and wrapped in a flexible cloth. Subsequent recordings were taken immediately after $48 \mathrm{~h}$ of the kangaroo position and finally at term-equivalent age $(40 \pm 1$ weeks). The newborns were kept in the kangaroo position for $8-12 \mathrm{~h} /$ day until the evaluation after $48 \mathrm{~h}$. They were removed from the 
Table 1 Clinical and biological characteristics of newborns

\begin{tabular}{lccc}
\hline & PT-KAN $(\mathbf{n}=\mathbf{2 5})$ & PT-NKAN $(\mathbf{n}=\mathbf{1 3})$ & T $(\mathbf{n}=\mathbf{2 6})$ \\
\hline Variables relating to newborn & & & \\
Gestational age, weeks & $31.06(2.24)$ & $31.21(1.68)$ & $39.27(0.92)$ \\
Birth weight, g & $1314(391.66)$ & $1433.08(349.72)$ & $3191.36(476.06)$ \\
Apgar score after 5', median (minimum-maximum) & $9(7-10)$ & $9(7-9)$ & $9(8-10)$ \\
Corrected age on first measurement $(0 \mathrm{~h}$ ), weeks & $34.86(1.66)$ & $33.93(1.17)$ & $39.84(0.85)$ \\
\hline
\end{tabular}

For continuous variables, the mean (SD) is given; for ordinal variables (Apgar), the median (minimum-maximum).

PT-KAN, preterm newborns in the kangaroo position; PT-NKAN, preterm newborns not in the kangaroo position.

kangaroo position (and placed on a soft cushion) for short intervals when the mothers would go to the restroom or to take a shower, during breastfeeding or other forms of feeding.

The measurements in the PT-NKAN group were made at $0 \mathrm{~h}$ and $48 \mathrm{~h}$. In the T group, electromyographic activity was measured only once at a chronological age of until $24 \mathrm{~h}$.

During data collection, the researchers asked the Kangaroo Unit not to give the newborns physiotherapy. The newborns did not therefore undergo any kind of early motor stimulation during data collection, except for oral stimulation done by speech therapists, when it was necessary.

\section{Treatment of data and statistical analysis}

The muscle activity analysis signal was transformed to the Root Mean Square (RMS) and normalised. ${ }^{20}{ }^{21}$ For normalisation, $100 \%$ corresponding to the maximum peak of the electromyographic signal was taken as a reference. A period of $10 \mathrm{~s}$ of total electromyographic reading (30 s) was used.

The comparison of means of the groups was carried out after verifying the normality of the distribution (Kolmogorov-Smirnov test) and the homogeneity of variance (Levene test), by repeated measurements analysis of variance, followed by multiple comparisons (Holm-Sidak's post hoc test) to test for the differences between each of the two groups. The $\alpha$ error for rejection of the null hypothesis was 0.05 .

\section{RESULTS}

The clinical and biological characteristics of the newborns in each group are presented in table 1.

The comparison on variance analyses of the RMS among measurements (table 2) demonstrated a significant difference $\left(\mathrm{F}_{(5,108)}=56.69 ; \mathrm{p}<0.001\right)$. The post hoc multiple comparisons (Holm-Sidak method) showed that in the PT-KAN group, the RMS was greater at $48 \mathrm{~h}$ $(p=0.004)$ and age equivalent to term measurement was $(\mathrm{p}=0.004)$ compared with the measurement at $0 \mathrm{~h}$, but there was no statistically significant difference between the measurements at $48 \mathrm{~h}$ and age equivalent to term. In the PT-NKAN group, no significant difference was found between $0 \mathrm{~h}$ and $48 \mathrm{~h}$.
The RMS in the PT-KAN group at age equivalent to term was greater than in the $\mathrm{T}$ group $(\mathrm{p}=0.004)$.

\section{DISCUSSION}

The results of this study showed an increase in electromyographic activity of the brachial biceps muscle in preterm newborns maintained at a kangaroo care environment for $48 \mathrm{~h}$ even when placed in the kangaroo position for $8-12 \mathrm{~h} /$ day, which did not occur in the control group. These data suggest that the kangaroo position changes myoelectrical activity in these newborns, at least in the flexor muscle case evaluated here.

A similar result was observed in a previous study. ${ }^{17}$ Preterm newborns placed for $24 \mathrm{~h}$ in the kangaroo position had an increase in the myoelectrical activity of flexor muscles, and this increase persisted even after $24 \mathrm{~h}$ out of this position.

In a later study, Diniz et $a l^{16}$ observed a growing increase in electromyographic activity in the brachial biceps muscle during $96 \mathrm{~h}$ in the kangaroo position. As in our study, this effect was observed $48 \mathrm{~h}$ after being placed in the kangaroo position. However, it is important to note the presence of the control group in our study, which added weight to our results. Also, according to Diniz et $a l \mathrm{~s}^{16}$ findings, the effect on electromyographic activity remained constant until an age equivalent to term.

Table 2 Electromyographic activity (RMS normalised) of the left brachial biceps muscle in preterm newborns in the kangaroo position or not and in term newborns

\begin{tabular}{|c|c|c|c|}
\hline \multirow{2}{*}{$\begin{array}{l}\text { Intervals } \\
\text { between } \\
\text { measurements }\end{array}$} & \multicolumn{3}{|l|}{ Groups } \\
\hline & $\begin{array}{l}\text { PT-KAN } \\
(\bar{X} \pm S D)\end{array}$ & $\begin{array}{l}\text { PT-NKAN } \\
(\bar{X} \pm S D)\end{array}$ & $\mathbf{T}(\overline{\mathrm{X}} \pm \mathrm{SD})$ \\
\hline & & $37.59 \pm 4.42$ & - \\
\hline & & $38.17 \pm 3.10$ & - \\
\hline TEA and TA & $48.03 \pm 5.56$ & - & $27.12 \pm 5.7$ \\
\hline
\end{tabular}

Analysis of variance for repeated measurements: $F_{(5,108)}=56.69$; $\mathrm{p}<0.001$. Multiple comparisons (Holm-Sidak test): in the PT-KAN group: $0 \mathrm{~h} \times 48 \mathrm{~h}(\mathrm{p}=0.004), 0 \mathrm{~h} \times T E A(\mathrm{p}=0.004)$. Between the PT-KAN and T groups: TEA $\times$ TA $(p=0.004)$.

PT-KAN, preterm newborns in the kangaroo position; PT-NKAN, preterm newborns not in the kangaroo position; RMS, Root Mean Square; SD, standard deviation; T, term newborns; TA, term age (for T group); TEA, term equivalent age (for the PT-KAN group). 
It is worth noting that the electromyographic activity in the PT-KAN group, at an age equivalent to term, was significantly greater than that in term newborns, although a similarity between them was expected. This increased electromyographic activity might be associated with the fact that preterm newborns received extrauterine stimuli at age equivalent to term, especially those provided by the kangaroo position. However, term newborns do not have the opportunity to receive such stimuli.

The effect of the kangaroo position in inducing a more flexed posture in preterm neonates is already known, ${ }^{22}{ }^{6}$ and this also suggests a specific effect of the kangaroo position on flexor muscles.

Recently, Schneider et $a t^{23}$ used transcranial magnetic stimulation, showing that preterm newborns undergoing the KM had better connectivity and synaptic efficacy of the motor routes in the brain at adolescence. Another study ${ }^{24}$ provided electroencephalic evidence to the effect that kangaroo interventions make the brain mature faster in healthy preterm newborns. These findings are relevant since changes in the myoelectrical parameter in response to the kangaroo position found in our study may be associated with faster maturation of the brain and better performance of the cerebral structures controlling motor activity. The mechanism behind this central motor activation on the peripheral myoelectrical response is still a matter to study, but it corroborates the conclusion that the kangaroo position has an effect on the muscle response.

Delays in neuropsychomotor development are frequent in preterm newborns owing to insufficient organisation of their nervous systems. ${ }^{823}$ However, a recent meta-analysis ${ }^{25}$ concluded that early intervention programmes for premature babies have a positive influence on motor development and there is evidence that tactile, synaesthetic and vestibular stimuli may influence the motor abilities of the newborns. ${ }^{26} 27$

We suggest, then, that early initiation of the kangaroo position may, like other early intervention programmes, have a positive influence on the motor development of preterm newborns. This hypothesis may be sustained by the characteristics on the kangaroo position, which provide different stimuli for the newborn. Therefore, considering that in the kangaroo position the preterm newborn remains in skin-to-skin contact with the adult breast, with its limbs flexed, in a vertical position ${ }^{1}$ and receives various environmental inputs, such as sensory, postural and vestibular stimuli, the kangaroo position ${ }^{16}$ may cause a considerable increase in motor activity. This evidence suggests that the kangaroo position has a positive influence on the motor activity in newborns that is physiologically represented by an alteration in the myoelectrical parameters as observed here. Moreover, the myoelectrical alterations in the flexor muscle are a relevant physiological response, since the kangaroo position maintains a flexed posture.

One limitation of this study is the absence of PT-NKAN (preterm newborns not submitted in the kangaroo position) followed up to age equivalent to term. Such a fact could clarify whether the increased electromyographic activity in the PT-KAN (preterm newborns in the kangaroo position) group at age equivalent to term is only related to the growth and development of the neonates or the influence of the kangaroo position. However, the reduced myoelectrical response in the $\mathrm{T}$ group suggests that it is the kangaroo position and not the growth of the newborns per se that is responsible for the changes in the electromyographic activity observed here. Apart from this limitation, the sample size was lower than the estimate, so it is a factor that may diminish the reliability of our findings. However, with a sample power of $90 \%$, the large differences found between the means and statistically significant results may support our inferences.

In conclusion, although this is a preliminary study resulting to provide evidence that the kangaroo position in the short term induces an increase in the myoelectrical activity in preterm newborns, which persists until the age equivalent to term. In addition, it may be a fact that electromyographic activity in premature newborns at age equivalent to term is greater than that in term newborns and related to the different stimuli (tactile, synaesthetic and vestibular) that they have received. It is suggested that this intervention induces changes in the flexor muscle function (flexor tonus), thereby making it possible to influence the motor development of the newborns. The age to which (in long terms) these effects persist and whether they have positive effects need to be examined in further studies.

It is important to point out the innovative nature of this study, although preliminary, since there is a lack of studies specifically evaluating electromyographic activity in newborns in the kangaroo position. Further research should be carried out to investigate the effect of the kangaroo position in electromyographic activity on other muscles involved in the postural system, both in preterm and term newborns.

Acknowledgements The authors thank the babies, parents and especially the nursing technicians at the Kangaroo Unit at the Instituto de Medicina Integral Professor Fernando Figueira (IMIP), Recife, Brazil. They would also like to thank the translators Patricia Ferraz and Peter Ratclisse (Sharing English Traduções) for editing the text in the English language.

Contributors RMM was involved in the preparation of the study project, data collection and supervision thereof, statistical analysis, research articles in the database and preparation of the article; he also approved the final manuscript as submitted; JECF was involved in offering guidance for the preparation of the study project, supervision of data collection, statistical analysis, research articles in the database; guidance and preparation of the article; he also approved the final manuscript as submitted; KTD was involved in the preparation of the study project, data collection and supervision thereof, data processing, statistical analysis, research articles in the database and preparation of the article; he also and approved the final manuscript as submitted; GMSL was involved in the preparation of the study project, data collection and supervision thereof; he also approved the final manuscript as submitted; DdAV was involved in the preparation of the study project, supervision of data collection and data processing; he also approved the final manuscript as submitted.

Funding Fundação de Amparo à Ciência e Tecnologia do Estado de Pernambuco-FACEPE (APQ—0552-4.08/100) and Fundo de Apoio à Pesquisa e Ensino do IMIP (FAPE-IMIP). 
Competing interests RMM was supported by the postgraduate scholarship from the Coordenaçã̃o de Aperfeiçoamento de Pessoal de Nível Superior (CAPES) and KTD was supported by the postgraduate scholarship from Fundação de Amparo à Ciência e Tecnologia do Estado de Pernambuco (FACEPE).

Patient consent Obtained.

Ethics approval The project for this study was submitted to IMIP's Ethics Committee for Research involving Human Beings and was approved (protocol number 1902).

Provenance and peer review Not commissioned; externally peer reviewed.

Data sharing statement No additional data are available.

Open Access This is an Open Access article distributed in accordance with the Creative Commons Attribution Non Commercial (CC BY-NC 4.0) license which permits others to distribute, remix, adapt, build upon this work noncommercially, and license their derivative works on different terms, provided the original work is properly cited and the use is non-commercial. See: http:// creativecommons.org/licenses/by-nc/4.0/

\section{REFERENCES}

1. Nyqvist $\mathrm{KH}$, Anderson GC, Bergman N, et al. Towards universal Kangaroo Mother Care: recommendations and report from the First European conference and Seventh International Workshop on Kangaroo Mother Care. Acta Paediatr 2010;99:820-6.

2. Mori R, Khanna R, Pledge D, et al. Meta-analysis of physiological effects of skin-to-skin contact for newborns and mothers. Pediatr Int 2010;52:161-70.

3. Almeida CM, Almeida AFN, Forti EMP. Effects of kangaroo mother care on the vital signs of low-weight preterm newborns. Rev bras fisioter 2007;11:1-5.

4. Johnston C, Campbell-Yeo M, Fernandes A, et al. Skin-to-skin care for procedural pain in neonates. Cochrane Database Syst Rev 2014 (4):CD008435.

5. Begum EA, Bonno M, Ohtani N, et al. Cerebral oxygenation responses during kangaroo care in low birth weight infants. $B M C$ Pediatr 2008:51:1-9.

6. Ferber SG, Makhoul IR. The effect of skin-to-skin contact (Kangaroo Care) shortly after birth on the neurobehavioral responses of the term newborn: a randomized, controlled trial. Pediatrics 2004;113:858-65.

7. Lamy Filho F, Silva AA, Lamy ZC, et al. Evaluation of the neonatal outcomes of the kangaroo mother method in Brazil. J Pediatr (Rio J) 2008;84:428-35.

8. Ludington-Hoe SM, Johnson MW, Morgan K, et al. Neurophysiologic assessment of neonatal sleep organization: preliminary results of a randomized, controlled trial of skin contact with preterm infants. Pediatrics 2006;117:e909-23.

9. Saeidi R, Asnaashari Z, Amirnejad M, et al. Use of "kangaroo care" to alleviate the intensity of vaccination pain in newborns. Iran $J$ Pediatr 2011;21:99-102.
10. Nimbalkar SM, Chaudhary NS, Gadhavi KV, et al. Kangaroo Mother Care in reducing pain in preterm neonates on heel prick. Indian $J$ Pediatr 2013;80:6-10.

11. Moore ER, Anderson GC, Bergman N, et al. Early skin-to-skin contact for mothers and their healthy newborn infants. Cochrane Database Syst Rev 2013;(6):CD003519.

12. Mahmood I, Jamal M, Khan N. Effect of mother-infant early skin-to-skin contact on breastfeeding status: a randomized controlled trial. J Coll Physicians Surg Pak 2011;21:601-5.

13. Nagai S, Yonemoto N, Rabesandratana N, et al. Long-term effects of earlier initiated continuous Kangaroo Mother Care (KMC) for low-birth-weight (LBW) infants in Madagascar. Acta Paediatr 2011;100:e241-7.

14. Conde-Agudelo A, Belizán JM, Diaz-Rossello J. Kangaroo mother care to reduce morbidity and mortality in low birthweight infants. Cochrane Database Syst Rev 2013;(6):CD002771.

15. Lawn JE, Mwansa-Kambafwile J, Horta BL, et al. Kangaroo mother care to prevent neonatal deaths due to preterm birth complications. Int J Epidemiol 2010;39:i144-54.

16. Diniz KT, Cabral-Filho JE, Miranda RM, et al. Effect of the kangaroo position on the electromyographic activity of preterm children: a follow-up study. BMC Pediatr 2013;13:79.

17. Barradas J. Kangaroo position effect on the flexor muscle tone of newborn preterm [Fernando Figueira: Dissertation]. Post Graduate Department the Institute of Integrated Medicine Prof; 2010.

18. Hermens HJ, Freriks B, Disselhorst-Klug C, et al. Development of recommendations for SEMG sensors and sensor placement procedures. J Electromyogr Kinesiol 2000;10:361-74.

19. Als H, Tronick E, Lester BM, et al. The Braselton neonatal behavioral assessment scale (BNBAS). J Abnorm Child Psychol 1977;5:215-29.

20. Bolgla LA, Uhl TL. Reliability of electromyographic normalization methods for evaluating the hip musculature. J Electromyogr Kinesiol 2007;17:102-11.

21. Lehman GJ, McGill SM. The importance of normalization in the interpretation of surface electromyography: a proof of principle. J Manipulative Physiol Ther 1999;22:444-6.

22. Barradas J, Fosceca A, Guimarães CLN, et al. Relationship between positioningof premature infants in kangaroo mother care and early neuromotor development. J Pediatr (Rio J) 2006;82:475-80.

23. Schneider C, Charpak N, Ruiz-Peláez JG, et al. Cerebral motor function in very premature-at-birth adolescents: a brain stimulation exploration of kangaroo mother care effects. Acta Paediatr 2012;101:1045-53.

24. Kaffashi F, Scher MS, Ludington-Hoe SM, et al. An analysis of the kangaroo care intervention using neonatal EEG complexity: a preliminary study. Clin Neurophysiol 2013;124:238-46.

25. Spittle A, Orton J, Anderson $\mathrm{P}$, et al. Early developmenta intervention programmes post-hospital discharge to prevent motor and cognitive impairments in preterm infants. Cochrane Database Syst Rev 2013;(6):CD005495.

26. Field TM, Schanberg SM, Scafidi F, et al. Tactile/kinesthetic stimulation effects on preterm neonates. Pediatrics 1986;77:654-58.

27. Symington AJ, Pinelli J. Developmental care for promoting development and preventing morbidity in preterm infants. Cochrane Database Syst Rev 2013;(6):CD 001814 